University of Vermont

UVM ScholarWorks

Public Health Projects, 2008-present

Public Health Projects, University of Vermont

College of Medicine

$1-23-2013$

\title{
Is Blood Donation an Opportunity for Hypertension Awareness?
}

\author{
J. Hao \\ C. Kerrigan \\ L. Kreiger \\ J. McAvoy \\ C. Sikavi
}

See next page for additional authors

Follow this and additional works at: https://scholarworks.uvm.edu/comphp_gallery

Part of the Community Health and Preventive Medicine Commons, and the Health Services Research Commons

\section{Recommended Citation}

Hao, J.; Kerrigan, C.; Kreiger, L.; McAvoy, J.; Sikavi, C.; Swift, D.; Wickberg, L.; Dembeck, C.; Frenette, C.; Carney, J.; and Fung, M., "Is Blood Donation an Opportunity for Hypertension Awareness?" (2013). Public Health Projects, 2008-present. 82.

https://scholarworks.uvm.edu/comphp_gallery/82

This Article is brought to you for free and open access by the Public Health Projects, University of Vermont College of Medicine at UVM ScholarWorks. It has been accepted for inclusion in Public Health Projects, 2008-present by an authorized administrator of UVM ScholarWorks. For more information, please contact scholarworks@uvm.edu. 


\section{Authors}

J. Hao, C. Kerrigan, L. Kreiger, J. McAvoy, C. Sikavi, D. Swift, L. Wickberg, C. Dembeck, C. Frenette, J. Carney, and M. Fung 


\section{Introduction}

Blood centers serve as a cornerstone of public health by providing potentially lifesaving blood products. Interactions with millions of potential donors provides these centers with a unique means of health education and screening opportunities ${ }^{1,2}$.

- Hypertension screening is one potentially feasible option in these centers. Hypertension, a modifiable risk factor affecting one in three adults, contributes to nearly half of all cardiovascular disease related deaths in the U.S. ${ }^{3}$. 14.1 million U.S. adults are unaware of their hypertension ${ }^{4}$, which has designated this disease "the silent killer."

- Blood pressure screening is required in the United States for the donation of blood. Many hypertensive donors, even those who are deferred for this reason, are never educated on the meaning of their blood pressure results.

- Numerous studies have evaluated the efficacy of blood centers in screening populations for risk factors ranging from

hyperlipidemia and hyperglycemia ${ }^{5,6}$ to genetic diseases ${ }^{7}$.

\section{Our study seeks to determine:}

1. How many donors fall within the pre-hypertensive or hypertensive blood pressure range based on their reading at the time of donation.

2. How many at-risk donors are not aware of these hypertensive or pre-hypertensive readings.

3. Whether blood centers can effectively provide blood pressure education by means of an informational pamphlet.

\section{Methods}

- 1200 voluntary and anonymous 25-question surveys were distributed to presenting blood donors through the Red Cross in VT and NH and collected from 10/10/12 to 10/26/12. - Deferred donors could still participate in the study

- Participants first answered twenty-two questions, then read an informational pamphlet about hypertension. Three additional questions were asked regarding the utility of this handout. - Prehypertension/hypertension was defined as having either a diastolic or systolic blood pressure measurement falling into the respective range.

- Data was double-entered into Microsoft Excel 2010 and

crosschecked for accuracy.

• Descriptive statistical analysis was done using SPSS.

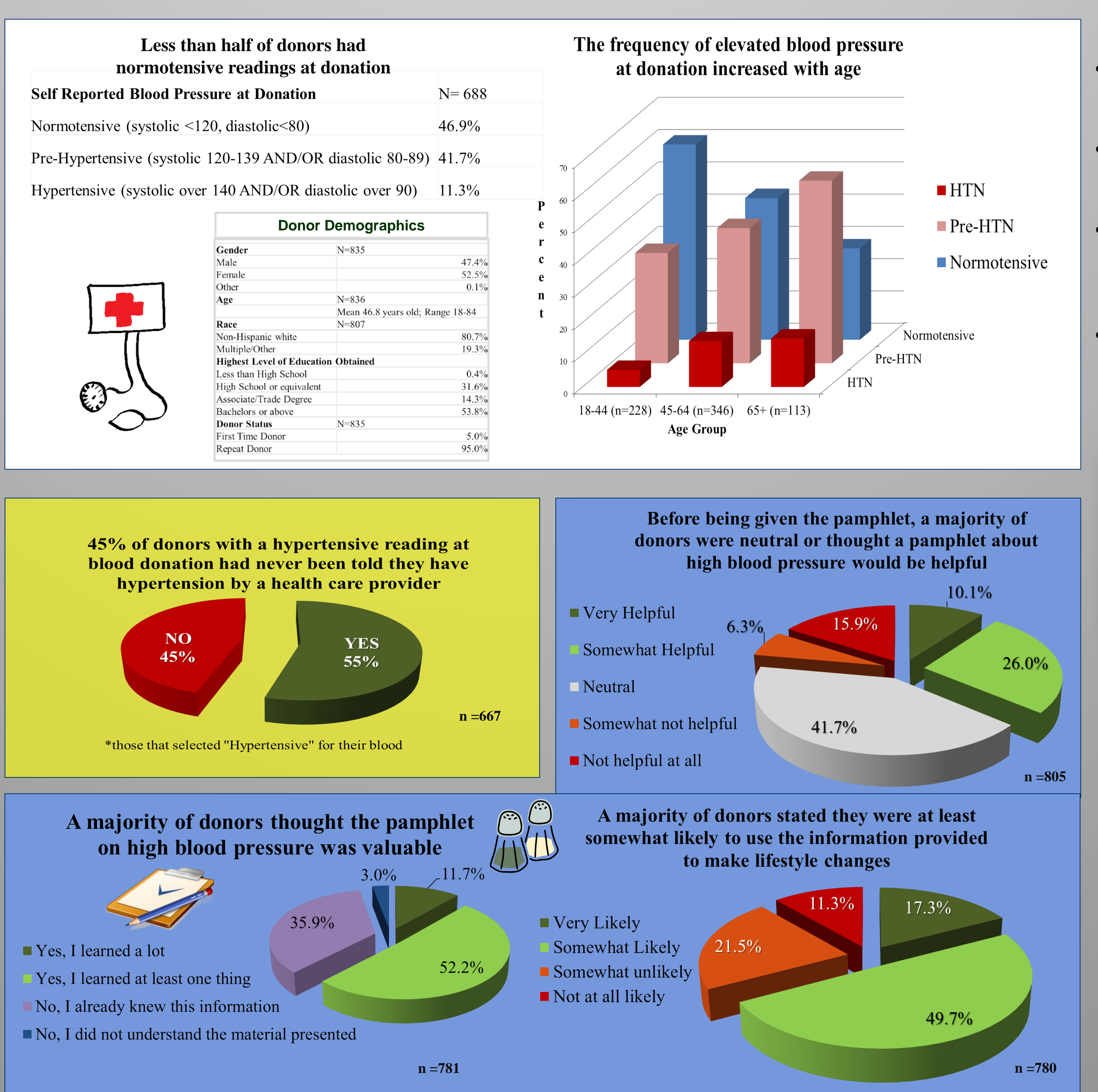

Conclusions

- Based on these findings, we conclude that there is an opportunity for increasing hypertension awareness at the time of blood donation.

- Within the highest risk group, those reporting a hypertensive blood pressure, almost half of them had not ever been told they had hypertension.

- In addition, the surveyed donors largely felt that the pamphlet of educational material about hypertension was valuable and were at least somewhat likely to use that information to make lifestyle changes.

- These findings suggest that increasing hypertension awareness as part of a blood donation screening is not only needed, but useful as a public health measure.

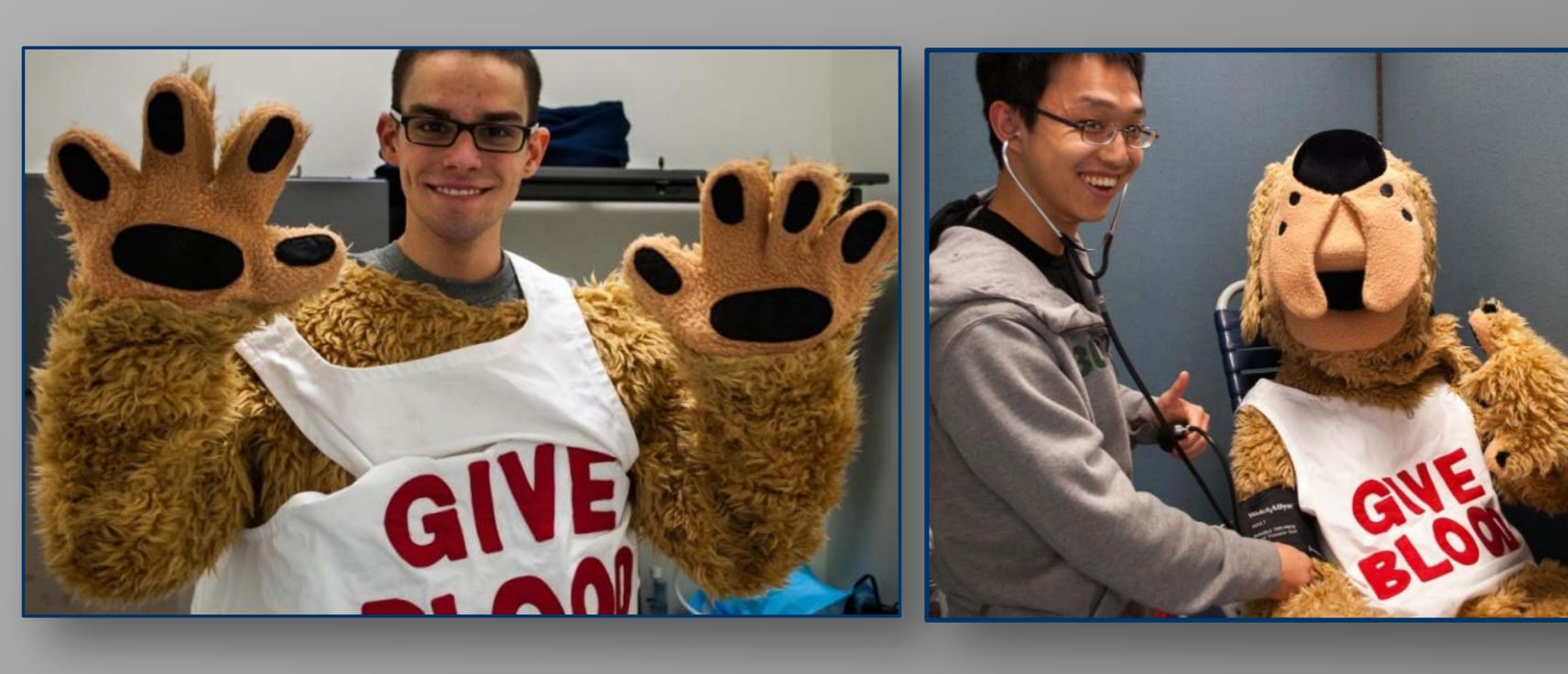

Acknowledgements

Tom Delaney, Ph.D; ARC Collection Staff and Supervisors. Nancy Gostyla, RN, Kathleen Bovat, RN Kristy Corbett, RN \& Marni Willms, RN; Volunteers of Bennington, White River Jct., Shelburne, Rochester, Montpelier, Troy Richford, Charlotte, Burlington \& Williston VT. Communities. Colebrook, Canaan \& Groveton NH Communities. Also, University of VT, Green Mountain College, Dartmouth College, Fletcher Allen, Alice Peck Day Hospitals and Green Mountain Coffee Roasters

\section{References} Davey RJ. Vox sanguinis. 2006;91(3):206-13. 2012;26(1):58-67 . Centers for Disease C, et al. MMWR Morbidity and mortality weekly repor. Kessler DA, et al. Transfusion. Online Only Feb 10, 2012 Geringer W, et al. Transfusion. 2004:44S:81A. 